\title{
STUDI SEMIEMPIRIS STRUKTUR MOLEKUL DAN BAND GAP MONOMER DAN DIMER 1,3,4 TIADIAZOL DAN DERIVATNYA
}

\author{
Emdeniz \\ Jurusan Kimia FMIPA Universitas Andalas Padang
}

\begin{abstract}
In order to know the possibility of compounds and their derivative for semiconductor material, moleculer structure and band gap (Eg) of these compounds need to be studied. This work included $1,3,4$ tiadiazole and 1,3,4 tiadiazole derivative with $-\mathrm{C} \equiv \mathrm{N}$ and $-\mathrm{C} \equiv \mathrm{CH}$ substituents. Each compounds was optimized by Calzaferri methods. The calculation results show that monomers and dimers 1,3,4 tiadiazole and thair derivative have $\mathrm{Eg}$ in the range of $2.89760 \mathrm{eV}$ to $4.35801 \mathrm{eV}$. These compounds has potential for basis of material organic semiconductor.
\end{abstract}

Keywords: Semiconductor, Band gap, Tiadiazole.

\section{PENDAHULUAN}

Seiring dengan berkembangnya ilmu pengetahuan dan teknologi, maka kebutuhan material semikonduktor yang mempunyai sifat dan karakteristik yang spesifik semakin meningkat. Pada dekade terakhir ini, penelitian material semikonduktor tertuju pada oligomer senyawa organik heterosiklik yang mempunyai ikatan $\pi$ berkonjugasi. Polimer ini mempunyai keunggulan dalam keragaman sifat mekanik, absorpsi optik dan ketransparanannya. Diantara beberapa polimer jenis ini, politiofen dan derivatnya cukup menarik untuk dipelajari lebih intensif. Politiofen cukup baik digunakan, karena mudah disintesis, akan tetapi beberapa oligomer derivat tiofen didapatkan kurang stabil dan prosesability nya kurang baik. Suatu masalah yang paling menonjol pada beberapa derivat tiofen ini ialah sangat mudah teroksidasi. Untuk itu perlu dicari oligomer derivat tiofen yang mempunyai sifat sulit teroksidasi, mempunyai band gap (Eg) sempit, mudah disintesis dan diproses serta mempunyai sifat absorpsi optik yang spesifik.

Aleman, Forni dan Espoti, telah melakukan penelitian semiempiris terhadap polimer tiofen, dengan beberapa metoda berbeda dan menyatakan bahwa polimer ini cukup potensial untuk digunakan sebagai material semikonduktor ${ }^{[1-3]}$. Politiofen relatif stabil dan mudah dibuat secara elektrokimia atau "oxidative coupling" dalam larutan serta dapat menyerap sinar tampak. Beberapa polimer derivat tiofen bersifat konduktor yang transparan. Menurut Deliere, adanya substituen aseptor elektron $\pi$ pada monomer dan polimer dapat memperbaiki efisiensi delokalisasi elektron sepanjang sistem $\pi$ diena dan mengakibatkan perubahan sifat hantaran listrik dan optik nonlinier material ${ }^{[4]}$.

Brocks and Tol, Nebutoki and Koezuka mengemukakan bahwa polimer/oligomer senyawa organik heterosiklik (mengandung $\mathrm{S}$, $\mathrm{N}$ dan $\mathrm{O}$ ) yang mempunyai $\pi$ berkonyugasi, berpotensi sebagai material semikonduktor ${ }^{[5,6]}$. Hal ini disebabkan karena polimernya dapat mempunyai Eg $1-3,5 \mathrm{eV}$, yang dikategorikan sebagai Eg semikonduktor. Hong dan Song mendapatkan bahwa polimer bisiklik dari (C6 H5 SX )n - dimana $\mathrm{X}$ adalah $\mathrm{CH}_{2}, \mathrm{C}=\mathrm{O}$, $\mathrm{C}=\mathrm{S}, \mathrm{C}=\mathrm{CH}_{2}$ dan $\mathrm{SiH}_{2}$ mempunyai Eg sekitar $0,2 \mathrm{eV}$ lebih kecil dari kopolimer tiofen ${ }^{[7]}$. Doping dengan logam tertentu pada polimer tiofen mengakibatkan struktur elektroniknya dan absorbsi optiknya akan mengalami perubahan. Salzner dengan menggunakan metoda B3P86-30\% mendapatkan penyempitan $\mathrm{Eg}$ politiofen, polipirol dan politiazol berbanding lurus dengan pertambahan $\operatorname{cincin}^{[8]}$. Hal ini dapat digunakan untuk peramalan nilai Eg oligomer/polimer suku tinggi dengan hanya melakukan penelitian semiempiris terhadap polimer yang 
disusun atas beberapa cincin monomer (5 atau 6 cincin monomer).

Demiralp dan Goddard mendapatkan bis(etilenditio)tetra thiavulvalen adalah donor yang sangat baik untuk superkonduktor organik $^{[9]}$. Brooks telah menggunakan polietilendioxytiofen (PEDOT) (band gap $2 \mathrm{eV}$ ) pada dioda, transistor dan dapat meningkatkan konduktifitas materia ${ }^{[10]}$. Polyisothianaptene (PTIN) mempunyai Eg $1 \mathrm{eV}$, tetapi polimer ini kurang stabil karena sangat mudah teroksidasi, sehingga penggunaannya semakin sempit. Menurut Delaere substitusi gugus donor $\left(-\mathrm{NH}_{2}\right.$, $\left.-\mathrm{N}\left(\mathrm{CH}_{3}\right)_{2}\right)$ dan aseptor $\left(-\mathrm{BH}_{2}\right)$ elektron $\pi$ pada posisi $\alpha$ pada monomer fosfol $\left(\mathrm{C}_{4} \mathrm{PH}_{4}\right)$ dapat memperbaiki efisiensi delokalisasi elektron sepanjang sistem $\pi$ diena dan dapat merubah sifat hantaran listrik dan optik nonlinier material ${ }^{[4]}$.

Berdasarkan studi literatur di atas, maka pada penelitian ini akan diarahkan pada oligomer derivat tiofen tersubstitusi nitrogen pada cincin, seperti oligomer tiadiazol. Pada penelitian awal ini diteliti struktur molekul dan band gap (Eg) monomer dan dimer 1,3,4-tiadiazol dan 1,3,4tiadiazol tersubstitusi gugus $-\mathrm{C} \equiv \mathrm{N}$, dan $\mathrm{C} \equiv \mathrm{CH}$. Kedua gugus ini termasuk kelompok aseptor elektron $\pi$ yang relatif baik. Sebelum dilakukan penelitian terhadap dimer 1,3,4 tiadiazol, terlebih dahulu dipelajari geometri dan sifat elektronik monomernya. Pada penelitian ini digunakan metoda Calzaferri yang berdasarkan teori Extended Huckel Molecular Orbital (EHMO) ${ }^{[11]}$.

Parameter atom dalam molekul pada dasarnya diambil dari elemen/unsur. Elektron yang ikut ambil bahagian dalam komputasi adalah elektron valensi atom bersangkutan. Orbital atom berbentuk fungsi gelombang yaitu $\varphi$ $(\mathrm{n}, \mathrm{z}, \mathrm{s})=\mathrm{r}^{\mathrm{n}-1} \exp ^{-(\mathrm{z}-\mathrm{s}) \mathrm{r} / \mathrm{n}}$, dengan $: \mathrm{n}=$ bilangan kuantum utama orbital, $\mathrm{z}=$ nomor atom, $\mathrm{s}=$ faktor screning akibat elektron-elektron lebih dekat ke inti dari pada elektron valensi ke inti, $\mathrm{r}=$ jarak inti atom dengan elektron. Biasanya nilai $(\mathrm{z}-\mathrm{s}) \mathrm{r} / \mathrm{n}=\xi$ ( $\xi$ disebut sebagai orbital eksponen). Pada metoda ini juga diperhitungkan energi repulsif $\left(\mathrm{E}_{\text {rep }}\right)$ yaitu energi tolakan antar atom dalam molekul dan energi total molekul $\left(\mathrm{E}_{\mathrm{T}}\right) . \mathrm{E}_{\mathrm{T}}=\Sigma \mathrm{E}_{\text {rep }}+\Sigma \mathrm{m}_{\mathrm{i}}$ $\mathrm{E}_{\text {номо }}+\Sigma \mathrm{n}_{\mathrm{k}}$ IP, dengan $\mathrm{m}_{\mathrm{i}}$ adalah jumlah elektron yang menduduki $\mathrm{OM}$ ke $\mathrm{i}, \mathrm{n}_{\mathrm{k}}$ adalah jumlah elektron yang menduduki orbital atom ke k. Untuk mendapatkan hasil penelitian yang akurat, perlu dilakukan modifikasi terhadap parameter atom ( $\xi$ dan IP) $\mathrm{C}, \mathrm{S}, \mathrm{N}$ dan $\mathrm{H}$ serta parameter atom ij $(1+\mathrm{k})$ molekul 1,3,4 tiadiazol dan 1,3,4 tiadiazol tersubstitusi yang akan diteliti. Parameter yang telah dimodifikasi ini digunakan untuk mendapatkan geometri molekul optimal serta ditentukan nilai $\mathrm{Eg}$ molekul pada keadaan tersebut. Parameter ini selanjutnya digunakan pada penelitian dimer 1,3,4 tiadiazol dan 1,3,4 tiadiazol tersubstitusi.

\section{METODOLOGI PENELITIAN}

Penelitian semiempiris ini dilakukan dengan menggunakan program Calzaferri yang dijalankan dengan IBM-PC Compatible. Proses optimasi molekul dilakukan secara manual, tunggal maupun ganda. Masukan yang diperlukan program adalah parameter atomatom dan koordinat atom dalam molekul. Semua parameter tersebut tersedia dalam program dan dapat dimodifikasi sesuai dengan keperluan penelitian. Luaran program berupa tingkat energi masing-masing orbital molekul $(\mathrm{OM})$ dalam molekul $\left(\mathrm{E}_{\mathrm{i}}\right)$, energi total molekul $\left(\mathrm{E}_{\mathrm{T}}\right), \mathrm{E}_{\mathrm{T}}=\Sigma \mathrm{n}_{\mathrm{i}} \mathrm{E}_{\mathrm{i}}$.

Panjang ikatan dan kekutan ikatan antar atom dalam molekul dan sebagainya (dapat disesuaikan dengan kebutuhan luaran penelitian). Setiap atom i atau pasangan atom ij akan dipengaruhi oleh lingkungan tempat atom tersebut berada. Dengan menvariasikan parameter atom penyusun molekul (tunggal atau berganda) kemudian diikuti dengan optimasi molekul (tunggal atau ganda) serta membandingkan luaran data (panjang ikatan antar atom) dengan data eksperimen atau X-ray, maka parameter yang telah dimodifikasi didapatkan. Dalam penelitian ini semua monomer, dimer dan substituennya dibuat planar.

Tahap pengerjaannya adalah sebagai berikut (1) Proses optimasi dilakukan terhadap monomer 1,3,4 tiadiazol dan 1,3,4 tiadiazol tersubstitusi $-\mathrm{C} \equiv \mathrm{N}$ dan $-\mathrm{C} \equiv \mathrm{CH}$. Tujuannya adalah untuk mendapatkan parameter termodifikasi yang cocok dan geometri molekul optimal serta Eg yang dipunyainya. Parameter $(1+\mathrm{k})$ ikatan pasangan atom $\mathrm{C} \alpha$ 
dengan atom $\mathrm{C}$ substituen $-\mathrm{C} \equiv \mathrm{N}$ dan $-\mathrm{C} \equiv \mathrm{CH}$, parameter atom $\mathrm{C}$ dan $\mathrm{N}$ (atom-atom kedua substituen) juga dimodifikasi. (2) Proses optimasi dilakukan untuk dimernya. Pada dimer ini parameter atom yang dipilih untuk dimodifikasi hanya parameter $(1+\mathrm{k})$ untuk antar cincin monomernya. Sedangkan untuk parameter yang lain digunakan parameter monomernya. (3) Dari nilai $\mathrm{E}_{\mathrm{HOMO}}$ dan $\mathrm{E}_{\text {LUMO }}$ nya pada keadaan geometri molekul optimal, yang ditunjukkan pada keadaan energi total $\left(\mathrm{E}_{\mathrm{T}}\right)$ paling minimum, dihitung Eg monomer, dimer $1,3,4$ tiadiazol dan $1,3,4$ tiadiazol tersubstitusi $-\mathrm{C} \equiv \mathrm{N}$ dan $-\mathrm{C} \equiv \mathrm{CH}$ dengan $\mathrm{Eg}$ adalah selisih $\mathrm{E}_{\mathrm{Lumo}}$ dengan $\mathrm{E}_{\text {Hомо. }}$

\section{HASIL DAN DISKUSI}

Sebahagian besar parameter atom penyusun molekul 1,3,4 tiadiazol dan substituennya mengalami perubahan (modifikasi). Hal ini dapat dipahami karena parameter yang tersedia pada program (parameter dasar) adalah berlaku untuk atom dalam keadaan bebas, sedangkan parameter yang digunakan pada atom dalam molekul sangat tergantung pada lingkungan atom tersebut berada.

Setelah parameter ini dimodifikasi, maka selanjutnya dasar ini digunakan untuk penelitian geometri molekul 1,3,4 tiadiazol dan $1,3,4$ tiadiazol tersubstitusi $-\mathrm{C} \equiv \mathrm{N}$ dan $-\mathrm{C} \equiv \mathrm{CH}$ sesuai dengan Gambar 1. Dari hasil optimasi geometri molekul tersebut (Tabel 2) terlihat bahwa akibat adanya gugus $-\mathrm{C} \equiv \mathrm{N}$ dan $-\mathrm{C} \equiv \mathrm{CH}$ pada 1,3,4 tiadiazol menyebabkan terjadinya perubahan beberapa panjang ikatan dan sudut ikatan pada cincin molekul. Adanya substituen ini memperkecil sudut ikatan S-C-N dan memperbesar sudut ikatan C-S-C.

Perubahan panjang ikatan dan sudut ikatan paling besar terlihat pada derivat HCC$\left(\mathrm{C}_{2} \mathrm{~N}_{2} \mathrm{~S}\right)-\mathrm{CCH}$. Gugus aseptor elektron $\pi-\mathrm{C} \equiv \mathrm{N}$ dan $-\mathrm{C} \equiv \mathrm{CH}$ menyebabkan bertambah panjangnya ikatan C-C dan C-N dan memperpendek ikatan N-N. Adanya substituen ini juga menyebabkan terjadinya perubahan nilai Eg molekul monomer.

$\mathrm{E}_{\text {номо, }} \mathrm{E}_{\mathrm{Lumo}}$ dan $\mathrm{Eg}$ monomer dan dimer 3,4 tiadiazol dan 3,4 tiadiazol tersubstitusi $-\mathrm{C} \equiv \mathrm{N}$ dan $-\mathrm{C} \equiv \mathrm{CH}$ pada Tabel 3 jelas terlihat Eg dari 1,3,4 tiadiazol relatif sempit $(4,35801 \mathrm{eV})$, dibandingkan dengan Eg monomer tiofen yang telah didapatkan Emdeniz yakni 5,0150 $\mathrm{eV}^{[12]}$. Hasil ini sesuai dengan yang telah dikemukakan Nebotuki dan Kuezuka dengan adanya atom $\mathrm{S}$ dan $\mathrm{N}$ yang mempunyai pasangan elektron sunyi, sangat besar sumbangannya pada delokalisasi elektron $\pi$ pada cincin. Adanya substituen aseptor elektron $\pi$ pada monomer mempengaruhi nilai Eg. Substituen $-\mathrm{C} \equiv \mathrm{N}$ menyebabkan $\mathrm{E}_{\mathrm{Lumo}}$ dan Еномо molekul semakin rendah serta mempersempit Eg dari 4,35801 eV menjadi 4,02873 atau 0,32928 eV. Sedangkan gugus $\mathrm{C} \equiv \mathrm{CH}$ ternyata dapat mempertinggi $\mathrm{E}_{\mathrm{HO} O}$ dan memperendah ELUMo dan Eg semakin sempit yakni 4,35801 eV menjadi $3,37574 \mathrm{eV}$ atau $0,98227 \mathrm{eV}$.

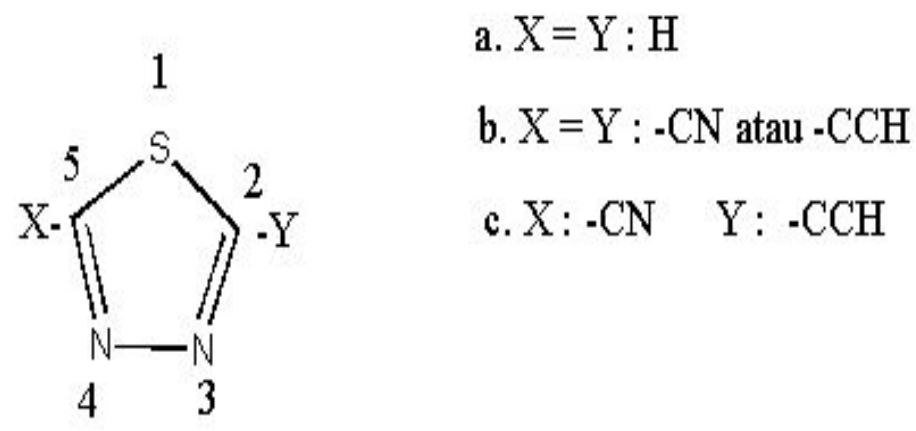

Gambar 1. a). Monomer $1,3,4$ tiadiazol, b). $1,3,4$ tiadiazol tersubstitusi $-\mathrm{CN}$ atau $-\mathrm{CCH}$ dan c). 1,3,4 tiadiazol tersubstitusi $-\mathrm{CN}$ atau $-\mathrm{CCH}$ 
Tabel 2. Panjang ikatan (Å) dan sudut ikatan (derajat) monomer 1,3,4 tiadiazol dan 1,3,4 tiadiazol tersubstitusi $-\mathrm{C} \equiv \mathrm{N}$ dan $-\mathrm{C} \equiv \mathrm{CH}$

\begin{tabular}{ccccc}
\hline \multirow{2}{*}{ Parameter } & \multicolumn{5}{c}{ Molekul } \\
\cline { 2 - 5 } Panjang ikatan & $\mathrm{C}_{2} \mathrm{~N}_{2} \mathrm{SH}_{2}$ & $\mathrm{NC}-\left(\mathrm{C}_{2} \mathrm{~N}_{2} \mathrm{~S}\right)-\mathrm{CN}$ & $\mathrm{HCC}-\left(\mathrm{C}_{2} \mathrm{~N}_{2} \mathrm{~S}\right)-\mathrm{CN}$ & $\mathrm{HCC}-\left(\mathrm{C}_{2} \mathrm{~N}_{2} \mathrm{~S}\right)-\mathrm{CCH}$ \\
$1-2$ & 1,721 & 1,720 & 1,737 & \\
$2-3$ & 1,302 & 1,324 & 1,329 & 1,744 \\
$3-4$ & 1,372 & 1,330 & 1,337 & 1,322 \\
$4-5$ & 1,302 & 1,324 & 1,392 & 1,346 \\
$5-1$ & 1,721 & 1,721 & 1,737 & 1,322 \\
Sudut ikatan & & & & 1,744 \\
$1-2-3$ & 112,38 & 111,08 & 110,20 & 110,33 \\
$2-3-4$ & 113,33 & 114,08 & 114,77 & 114,87 \\
$3-4-5$ & 113,33 & 114,24 & 114,29 & 114,87 \\
$4-5-1$ & 112,38 & 111,08 & 111,31 & 110,33 \\
$5-1-2$ & 88,54 & 89,34 & 89,45 & 89,60 \\
\hline Keterangan: Penomoran sesuai berdasarkan Gambar 1 & & &
\end{tabular}

Tabel 3. Eномо, ELumo, dan Eg monomer dan dimer 3,4 tiadiazol dan 3,4 tiadiazol tersubstitusi $-\mathrm{C} \equiv \mathrm{N}$ dan $-\mathrm{C} \equiv \mathbf{C H}$

\begin{tabular}{cccc}
\hline Molekul & Еномо $_{\text {Hо }}$ & E $_{\text {LUмо }}$ & $\mathrm{E}_{\mathrm{g}}$ \\
\hline $\mathrm{C}_{2} \mathrm{~N}_{2} \mathrm{SH}_{2}$ & $-12,10487$ & $-7,74686$ & 4,35801 \\
$\mathrm{NC}-\left(\mathrm{C}_{2} \mathrm{~N}_{2} \mathrm{~S}\right)-\mathrm{CN}$ & $-12,70509$ & $-8,67636$ & 4,02873 \\
$\mathrm{NC}-\left(\mathrm{C}_{2} \mathrm{~N}_{2} \mathrm{~S}\right)-\mathrm{CN}$ & $-11,96305$ & $-8,58731$ & 3,37574 \\
$\mathrm{HCC}-\left(\mathrm{C}_{2} \mathrm{~N}_{2} \mathrm{~S}\right)-\mathrm{CN}$ & $-11,97083$ & $-8,32642$ & 3,64441 \\
$\left(\mathrm{C}_{2} \mathrm{~N}_{2} \mathrm{~S}\right)_{2} \mathrm{H}_{2}$ & $-11,38637$ & $-8,33946$ & 3,04691 \\
$\mathrm{NC}-\left(\mathrm{C}_{2} \mathrm{~N}_{2} \mathrm{~S}\right)_{2}-\mathrm{CN}$ & $-11,88621$ & $-8,88861$ & 2,99760 \\
$\mathrm{HCC}-\left(\mathrm{C}_{2} \mathrm{~N}_{2} \mathrm{~S}\right)_{2}-\mathrm{CCH}$ & $-11,28005$ & $-8,38245$ & 2,89760 \\
$\mathrm{HCC}-\left(\mathrm{C}_{2} \mathrm{~N}_{2} \mathrm{~S}\right)_{2}-\mathrm{CN}$ & $-11,25115$ & $-8,27458$ & 2,97657 \\
\hline
\end{tabular}

Senyawa yang memiliki substituen $-\mathrm{C} \equiv \mathrm{N}$ dan $-\mathrm{C} \equiv \mathrm{CH}$ secara bersamaan pada monomer ternyata mempertinggi $\mathrm{E}_{\mathrm{HOMO}}$ dan

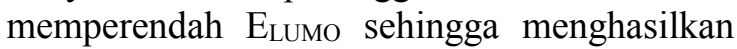
Eg yang lebih sempit, yakni terjadi perubahan dari 4,35801 eV menjadi 3,64441 $\mathrm{eV}$ atau
0,71360 eV. Penyempitan Eg terjadi karena gugus aseptor elektron akan meyebabkan efesiensi delokalisasi elektron $\pi$ disepanjang cincin. Hal ini jelas terlihat pada panjang ikatan $2-3,3-4$ dan $4-5$ pada $1,3,4$ tiadiazol tersubstitusi relatif tidak jauh berbeda. 
Keadaan ini berbeda dengan 1,3,4 tiadiazol tanpa adanya gugus $-\mathrm{C} \equiv \mathrm{N}$ dan $-\mathrm{C} \equiv \mathrm{CH}$, dimana panjang ketiga ikatan ini relatif jauh berbeda. Keadaan ini juga akan terlihat pengaruh efisiensi delokalisasi elektron $\pi$ pada dimer.

Delokalisasi elektron $\pi$ pada suatu cincin semakin baik ditandai dengan relatif samanya panjang ikatan pada cincin, seperti yang terjadi pada cincin benzen, yang merupakan contoh dari delokalisasi elektron $\pi$ yang dianggap paling sempurna, yang ditunjukan oleh panjang ikatan yang sama antara satu atom $\mathrm{C}$ dengan atom C lainnya. Monomer derivat 1,3,4 tiadiazol yang mempunyai substituen sama dan substituen $-\mathrm{C} \equiv \mathrm{N}$ dan $-\mathrm{C} \equiv \mathrm{CH}$ bersamaan pada posisi $\alpha$ sangat berpotensi dijadikan sebagai material oligomer senyawa organik semikonduktor. Dari perubahan Eg dari bentuk monomer dengan bentuk dimer di atas, dapat diperkirakan kurva Eg dengan pertambahan rantai oligomer 1,3,4 tiadiazol dan 1,3,4 tiadiazol tersubstitusi tidak mempunyai kemiringan yang sama. Untuk pembuktiannya masih perlu penelitian lanjutan untuk oligomer dengan 3 sampai 6 cincin monomer.

\section{KESIMPULAN}

Dari hasil penelitian semiempiris terhadap monomer dan dimer 1,3,4 tiadiazol serta derivatnya yang tersubstitusi $-\mathrm{C} \equiv \mathrm{N}$ dan $\mathrm{C} \equiv \mathrm{CH}$ dapat disimpulkan bahwa monomer dan dimer derivat 1,3,4 tiadiazol yang mempunyai substituen sama dan substituen $-\mathrm{C} \equiv \mathrm{N}$ dan $\mathrm{C} \equiv \mathrm{CH}$ bersamaan pada posisi $\alpha$ sangat berpotensi dijadikan sebagai molekul dasar untuk material oligomer senyawa organik semikonduktor, karena mempunyai band gap antara 2,89760 eV - 4,35801 eV. Substituen $\mathrm{C} \equiv \mathrm{N}$ dan $-\mathrm{C} \equiv \mathrm{CH}$ dapat menambah efisiensi delokalisasi elektron $\pi$ disepanjang cincin 1,3,4 tiadiazol.

\section{DAFTAR PUSTAKA}

1. C. Aleman, and L. Julia, Characterization of Quinoid Structure for the 2,2'Bithiophene and 2,2' 5',2'-Terthiophene
Cations, J. Phys. Chem., 100, 14661 14664, (1996).

2. A. Forni, M.Sironi, M. Raimondi, D. L. Cooper, and J. Gerrartt, Theoritical Investigation of Thiopene Oligomer : A Spin-Coupled Study, J. Phys. Chem. A, 101, 4437 - 4443, (1997).

3. A. S. Espoti, and F. Zerbetto, A Density Fungtional Study of the Vibrations of Three Oligomers of Thiophene, J. Phys. Chem. A, 101, 7283 - 7291, (1997).

4. D. Delaere et al., Theoretical Study of the Structure-Property Relationship in Phosphole Monomers, J. Org. Chem., 65, 2631-2636, (2000).

5. G. Brocks, and A. Tol, Small Band Gap Semiconducting Polymers Made from Dye Molecules: Polysquaraines, J. Phys. Chem., 100, 1838 - 1846, (1996).

6. H. Nebutoki, and H. Koezuka. Molecular Orbital Study on Confinement Characteristics in Heteroaromatic Oligomer. J. Phys. Chem., 100, 6451 6455, (1996).

7. S.Y. Hong and J.M. Song, Qantum Chemical Study of Geometrical and Electronic Structures of Thiophene-Based Bicyclic Polymer, J. Phys. Chem., 101, 10248 - 10253, (1997).

8. U. Salzner, P. G. Pickup, and R. A. Poirier, Accurate Method for Obtaining Band Gaps in Conducting Polymer Using a DFT/Hybrid Approach, J. Phys. Chem. A, 102. 2572-2578, (1998).

9. E. Demiralp, and W. A. Goddard III, Structures and Energetics Study of Tetrathiafulvalene-Based Donor of Organic Superconductors, J. Phys. Chem. $A, 101,8128$ - 8131, (1997).

10. G. Brocks, Density Fungtional Study of Polythiophene Derivates, J. Phys. Chem, 100, 17327 - 17333, (1996).

11. G. Calzaferri, and M. Brandle, Quantum Chemistry Program Exchange (QCPE Program No. QCMP 116), Indiana University, Bloomington, Indiana, 1993.

12. Emdeniz, Mempelajari Geometri dan Sifat Elektronik Oligomer Tiofen, Laporan Penelitian Dosen Muda (BBI), No. Kontrak 005/LIT/BPPK-SDM/III/2001, Departemen Pendidikan Nasional, 2001. 